\title{
EFFECTS OF SPATIAL SEPARATION AS A GUE OF TIME ESTIMATION IN CHILDREN AND ADULTS
}

\author{
FUMIKO MATSUDA ${ }^{1}$ AND MICHIHIKO MATSUDA \\ Hiroshima Women's University \\ Chiba Universily ${ }^{2}$
}

\begin{abstract}
It was confirmed by the reproduction method in children of 7 to $10 \mathrm{yrs}$. and adults that (a) as subjects were younger, the kappa effect was stronger, and that (b) the kappa effect was stronger under the condition where subjects were assumed to form the set more easily in using the spatial separation as a cue for time estimation than under conditions where they are assumed to form the set less easily. These findings verified that the kappa effect in successively presented static stimuli was not contradictory to the hypothesis of "cue-selection sets" which was interpreted from the results of the first author's previous studies on a moving stimulus.
\end{abstract}

Many studies have been concerned with psychological relativity in the perception of time and distance. The effect of spatial separation on the estimation of temporal interval is known as the kappa effect. That is, the greater the spatial separation between two successively presented stimuli with a constant temporal interval (the standard interval) is, the greater the temporal interval between comparison stimuli presented with a constant spatial separation should be to match with the standard stimuli in apparent interval.

In visual perception, many investigators, such as, Abbe (1936, 1937), Abe (1935), Adkins (1972), Bonnet (1965), Cohen, Hansel, and Sylvester (1953, 1955), Matsuda and Matsuda (1979), Parks (1968), Price-Williams (1954), and Voyat (1963) observed the effect with quite different stimuli and methods (Matsuda, 1970). Several investigators have obtained the same effect of spatial separation on the time estimation by changing the spatial separations only apparently but keeping

1 The authors express their deep gratitude to Professor T. Oyama, Chiba University, for critical reading and helpful suggestions.

Requests for reprints should be sent to Fumiko Matsuda, Hiroshima Women's University, Ujinahigashi, 1-1-71, Hiroshima, 734 Japan.

2 Now at Kochi Medical School. them physically constant, by means of the Müller-Lyer illusion (Lebensfeld \& Wapner, 1968; Sudo, 1941) or different gradient texture surfaces (Newman \& Lee, 1972). In these investigations, except the study by Voyat (1963), subjects were all adults, He used seven- and eight-year-old children besides adults as subjects. But these children showed the effect which was apparently in the opposite direction to the kappa effect. In his experiment standard temporal intervals with shorter spatial separations were compared with variable temporal intervals with longer spatial separations and percentages of judgement in which the variable ones were perceived shorter than the standard ones were above $50 \%$. In experiments by Abbe (1963) 11 years old boy showed the kappa effect in the same way as adults. There seems to be no studies which examined systematically the kappa effect from the view point of mental development, though the effect has long been studied for adult subjects by many investigators.

One of the present authors (Matsuda, $1968,1969,1970,1971,1974,1977)$ has used a moving stimulus in place of successively presented static stimuli and examined developmentally interdependence among duration, path-length and velocity in their estimations. On the basis of these 
results she has proposed a hypothesis of "cue-selection sets". Namcly, the time estimation (or the distance estimation) is influenced by the subject's set to select as the estimation cue either one of the two stimulus dimensions, that is, distance and velocity (or time and velocity). With this hypothesis, she tried to account for not only the psychological relativity in the estimation of duration and path-length in a moving stimulus, but also those in static stimuli (kappa and tau effects). This hypothesis was concerned with both the effect of physical path-length on the duration estimation (kappa effect) and the effect of physical duration on the path-length estimation (tau effect), but the present study is concerned with only the first one.

According to this hypothesis, in the case of a moving stimulus, an effect which was in the same direction as the kappa effect was expected to occur under the situation where subjects were assumed to form the set to use the physical path-length rather than the physical velocity as the cue for the duration estimation, because the physical path-length varies in direct proportion to the physical duration when the physical velocity is held constant. Another effect which was in the opposite direction to the kappa effect was expected to occur under the situation where subjects were assumed to form the set to use the physical velocity rather than the physical path-length as the cue for the duration estimation. The reason is that, as the physical velocity varies in inverse proportion to the physical duration when the physical path-length is constant and in direct proportion to the physical pathlength when the physical duration is constant, the physical duration is inversely proportional to the physical path-length through the intermediation of the physical velocity. Both of these expectations have been confirmed in her experimental studies (Matsuda, 1970, 1971, 1974, 1977). On the other hand, in the case of static stimuli, it was assumed that the set to use the spatial separation as the cue for the estimation of temporal interval was gencrally formed in subjects and they could not choose velocity as the cue. So that, the kappa effect was properly expected to occur as in the results of many investigations.

In the case of static stimuli, it is also predicted from the hypothesis that the kappa effect may be stronger under the condition where subjects are assumed to form more easily the set to use the spatial separation as the cue for the estimation of temporal interval than under the condition where they are assumed to form that set less easily. It is the first purpose of this paper to examine this prediction.

The developmental aspect of the hypothesis of "cue-selection sets" indicated that it was more difficult for young children to choose duration (or interval) as the cue than to choose spatial length (or separation) or velocity. This prediction was confirmed by the findings of Ono (1968a,b 1975). This hypothesis also predicted that it was very difficult for children to choose as the cue some stimulus dimension which was inversely proportional to the estimated stimulus dimension. From these prediction it is expected that as the subject becomes younger, centration to spatial separation in the estimation of temporal interval will be stronger, so that the kappa effect will be stronger. The second purpose of this paper is to test this expectation.

Piaget (1961) insisted that when an infant perceived an object in a situation he fixed his attention on only a certain element of the object or of the situation (centration) so that his perception is relatively subjective, and that with age he became generally to be able to attend comparatively equally to all elements in the situation (décentration) by the factor of compensation based on coordination of centrations and his perception became comparatively objective.

Studies of Cohen (1967), Fraisse (1966, 
1967), Fraisse and Vautrey (1952a, b), Zuili and Fraisse (1966, 1969), and Piaget $(1957,1969)$ suggested that interdependence among the perception of duration, spatial length and velocity changes at about age of eight or nine years through progressive décentration. In the present investigation a younger group ranging in age from six to seven years and an older group from nine to ten were used as subjects.

The reproduction method was used to measure subjective duration, because it was quick and fun enough for the children to attract their attention through the experimental sessions.

\section{METHOD}

Apparatus. The essential constituent parts of the apparatus were: (1) Three delayed timers (MTL; Matsushita electric works, LTD) for three kinds of standard intervals. (2) Another three delayed timers (Omron Solid State Timers; Omron tateisi electric Co.) for each of the presentation durations $(0.2 \mathrm{sec})$ of three successively presented stimuli. (3) A black wooden panel $(80 \mathrm{~cm}$ in height $\times 90 \mathrm{~cm}$ in width) with a black vertical screen $(5 \mathrm{~cm}$ in height $\times 90 \mathrm{~cm}$ in width). There were six slits ( $3 \mathrm{~cm}$ in height $\times 1 \mathrm{~mm}$ in width) at the center of the screen, at $3,6,12$, and $24 \mathrm{~cm}$ to right of the center, and at $9 \mathrm{~cm}$ to left of the center. Just behind each slit there was a lamp housing with two bulbs of $6 \mathrm{~V}$. (4) An electric key and a digital stop watch (Takei kiki kogyo Co.). (5) Fifteen relays (F, Bv. 153a, 51/1; Fujitsu Co.) in order to regulate on and/or off of the six delayed timers, bulbs in the six lamp housing, and the digital stop watch.

The method of time estimation. With this apparatus, the stimuli were presented in the following way. First, a light line $\left(50 \mathrm{~cd} / \mathrm{m}^{2}\right.$, $3 \mathrm{~cm}$ in height $\times 1 \mathrm{~mm}$ in width), which was designated as the first stimulus, was presented for $0.2 \mathrm{sec}$ on the right side of the black vertical screen which was positioned at $130 \mathrm{~cm}$ from the subject. Then the second stimulus $\left(50 \mathrm{~cd} / \mathrm{m}^{2}, 3 \mathrm{~cm}\right.$ in height $\times 1 \mathrm{~mm}$ in width) was presented for $0.2 \mathrm{sec}$ at the center of the screen. Spatial separation between the two stimuli was either $3,6,12$, or $24 \mathrm{~cm}$, and the temporal interval between them was 1, 3, or $8 \mathrm{sec}$ and each of them was used as the standard interval. The third stimulus $\left(50 \mathrm{~cd} / \mathrm{m}^{2}\right.$, $3 \mathrm{~cm}$ in height $\times 1 \mathrm{~mm}$ in width) could be switched on for $0.2 \mathrm{sec}$ at $9 \mathrm{~cm}$ to the left of the center of the screen by pushing the electric key. At a position of $0.5 \mathrm{~cm}$ above the position where the third stimulus was set, there was always a small light point $\left(3.5 \mathrm{~cd} / \mathrm{m}^{2}, 1 \mathrm{~mm}\right.$ in diameter) in order to give the subject previous notice for the position of the third stimulus in each trial. The positions of the second and the third stimuli were held constant and only the position of the first one was changed by the experimenter.

The subject was asked to push the key by his hand to switch on the third stimulus at the moment when the temporal interval between the second and third stimuli was perceived exactly equal to the standard interval. In other words, the task of the subjects was to match the perceived temporal interval between the second stimulus and the third one to that between the first one and the second one, that is, the subjects reproduced the perceived temporal interval between the first stimulus and the second one. The reproduced interval was recorded by the digital stop watch.

The subject was asked not to count for estimating interval.

The subject who sat in front of the screen could see only light lines and a light point on the screen, because the experimental room was dark $(0.1 \mathrm{~lx})$ and all apparatus were black. Thus cues for time and distance estimations were very much reduced under this experimental condition.

Procedure. There were 12 stimulus conditions, all combinations between the four spatial separations and the three standard intervals. Each subject was given two trials for each condition in one session, a total of 24 trials in one session. A 10-min rest was given after the 12th trial, the first half of the session. The subject was given 24 trials in each of two sessions 
separated at least a week from the previous one. In one session, the presentation order was completely randomized concerning both the conditions of spatial separation and standard interval for each subject (Presentation Order R). On the other session, trials were grouped for each condition of spatial separation and only the condition of standard interval was randomized (Presentation Order S). By this procedure it would be expected that under Presentation Order $\mathrm{R}$ subjccts tended to form more easily the set to use spatial separation as the cue for the estimation of temporal interval as compared with Presentation Order S. The half of the subjects began from Presentation Order $R$ and the other half began from Presentation Order $\mathrm{S}$.

Subject. Twenty children of the first grade of an elementary school (Group E1), 20 children of the fourth grade (Group E4), and 20 undergraduate college students (Group $U$ ) served as subjects in the experiment. In each group the half of the subjects were male and the other half were female. The mean ages of Groups $\mathrm{E} 1, \mathrm{E} 4$, and $\mathrm{U}$ were seven years and four months, 10 years and six months, and 22 years and a month, respectively.

\section{Results}

Mean reproduced interval for each condition in each group is shown in Fig. 1. Analyses of variance with four way classification (Spatial separation $\times$ Presentation order $\times$ Sex $\times$ Age) were applied to the reproduced intervals (Table 1). As dispersions of reproduced intervals were considerably different for each standard interval condition, the analysis of variance was attempted for each standard interval condition separately.

Based on the result of the analyses of variance, $t$ tests in the .05 level were applied to differences between two conditions of Spatial separation, Presentation order or Age.

For the condition of standard interval of $1 \mathrm{sec}$, these results indicated: (1) The mean reproduced interval of male, $1.18 \mathrm{sec}$, was longer than that of female, $1.06 \mathrm{sec}$. (2) The mean reproduced interval of Group E4 was the shortest. (3) The mean reproduced interval increased as the spatial separation became longer. This effect of spatial separation was statistically significant only for Presentation Order R but not for Presentation Order S. Besides, the interaction between the spatial separation and the presentation order was more clear in Group E1 than in Group E4 and Group U.

For the condition of standard interval of $3 \mathrm{sec}$, the results of analysis of variance and $t$ tests indicated: (1) The mean reproduced interval of Group $U$ was the longest. (2) The mean reproduced interval increased as the spatial separation became longer. This effect of spatial separation was statistically significant only for Presentation Order $\mathrm{R}$ but not for Presentation Order S.

For the condition of standard interval of $8 \mathrm{sec}$, the results of analysis of variance and $t$ tests indicated: (1) The mean reproduced interval increased as the age of subjects increased. (2) The mean reproduced interval increased as the spatial separation became longer. This effect of spatial sep-

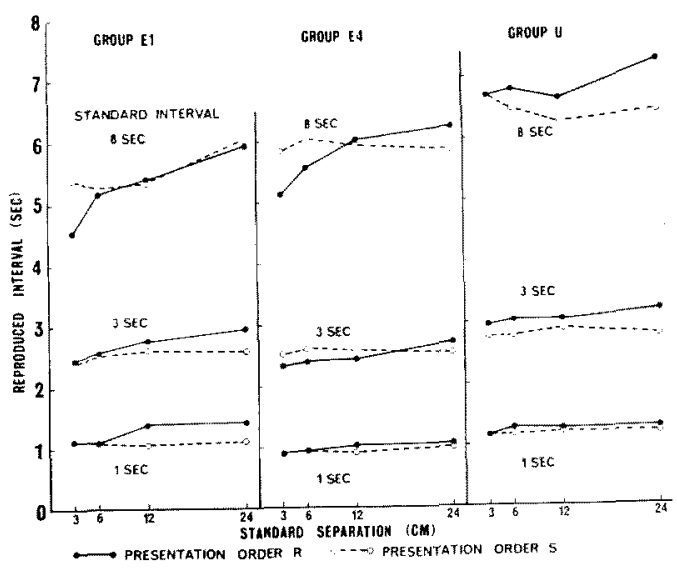

Fig. 1. Mean reproduced intervals under the two conditions of presentation order for each standard interval in each age group, combining data of males and females. 
TABLE 1

Analyses of variance applied to the reproduced interval for each standard interval condition separately

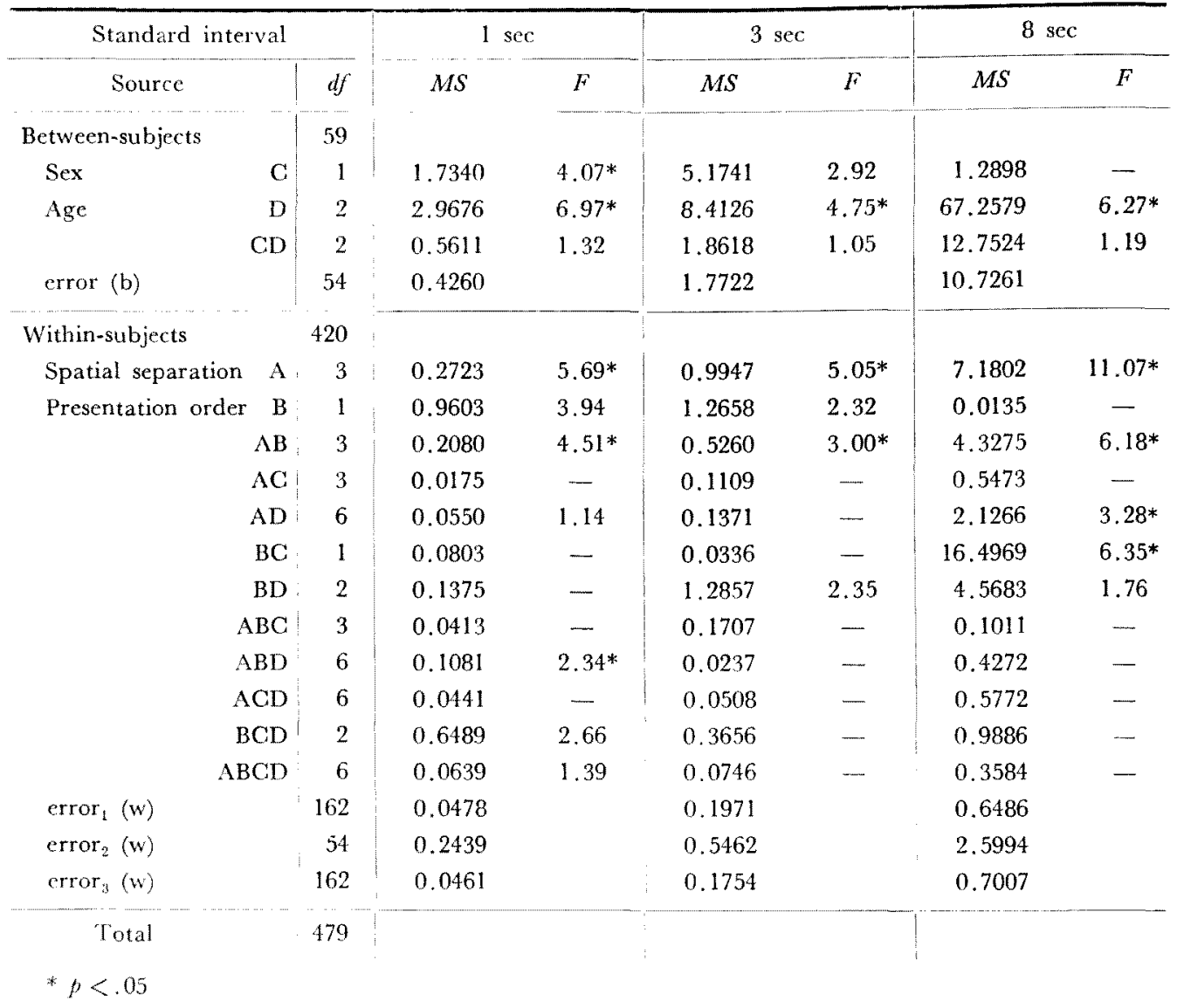

aration was statistically significant only for Presentation Order R but not for Presentation Order $\mathrm{S}$, and was stronger as the subject was younger. (3) In male subjects the mean reproduced intervals under Presentation Order R $(5.82 \mathrm{sec})$ were shorter than under Presentation Order S $(6.20 \mathrm{sec})$, but in female, vice versa $(6.07 \mathrm{sec}$ and 5.73 sec, respectively).

\section{DisGUSSION}

Under all conditions of standard intervals, the interactions between the spatial separation and the presentation order were significant, that is under the condition of
Presentation Order $\mathrm{R}$ the kappa effect was observed but under the condition of Presentation Order S it was scarecely observed. These findings verified one of the assumptions based on the hypothesis of "cueselection sets", that is, when the subject is expected to form easily the set to use the physical distance as the cue for time estimation he must show the kappa effect more strongly than when he is not expected to form that set easily. These results show that the first purpose of this study was attained. These findings were in accord with the results of Abbe (1936), who reported that the kappa effect almost disappeared when the subjects were asked to 
make the set to judge the temporal interval and the spatial separation as independently as possible.

For the standard interval of 1 sec, the subjects in Group El showed a stronger effect of the spatial separation under Presentation Order $R$ than in the other groups, and under the $8 \mathrm{sec}$ standard interval condition, the effect of spatial separation was stronger as the subjects was younger and the subjects of Group E1 showed the same effect even under Presentation Order S. These findings verified the other assumption, that the younger the subject is, the stronger the kappa effect is. That is, the second purpose of this study was attained. It was reported by Voyat (1963) that children between 7.6 and 8.6 years showed the effect in the opposite direction from the $k a p p a$ effect. His results seemed to be caused by strong time error for children.

From the developmental point of view another important finding should be noted, that is, the responses of Group E4 were more similar to those of Group $U$ rather than Group E1. This finding scems to support the suggestion by Cohen (1967), Fraisse (1966, 1967), and Piaget (1957, 1969), that interdependence among the perceptions of time, distance and velocity may change at about the age of eight or nine years through progressive décentration. That is, children of Group El did centrate strongly to the spatial separation when they estimated the temporal interval, especially when the spatial separation changed in direct proportion to change of temporal interval, but children of Group $\mathrm{E} 4$ and adults did relatively décentrate from the spatial separation and the temporal interval was estimated more objectively.

There was a slight difference among the three conditions of standard interval about the three main results above mentioned.

It is concluded that the kappa effect in the case of static stimuli is also in accord with the hypothesis of " cue-selection sets" which was led from the experimental results with a moving stimulus.

\section{REFERENCES}

Anne, M. 1936 Der räumliche Effekt auf die Zeitauffassung. Japanese fournal of Experimental Psychology, 3, 1-52. (In Japanese with German summary)

Aвbe, M. 1937 Der räumliche Effekt auf die Zeitaufrassung. II: Simultaner Vergleich der phänomenalen Grösse zweier Zeitstrecken, die durch Sukzessive-Darbictung dreicr Reize gegremat werden. Japanese Joumal of Experimental Psychology, 4, 1-12. (In Japanese with German summary)

ABE, S. 1935 Experimental study on the corelation between time and space. Tohoku Psychologica Folia, 3, 53-68.

Ankins, C.J. 1972 Verbal estimations of time of four spatial distances. Perceplual and Molor Skills, 35, 411-418.

Bonnet, C. 1965 Influence de la vitesse du mouvement et de l'espace parcouru sur l'estimation du temps. L'Année Psychologique, 65, $357-363$.

Conen, J. 1967 Psychological time in health and disease. Springfield, Ill.: Charles C. Thomas.

Cohen, J., Hansel, C.E.M., \& Sylvester, J. D. 1953 A new phenomenon in time judgment. Nalure, 172, 901 .

Cohen, J., Hansel, C.E.M., \& Syluestek, J. D. 1955 Interdependence in judgements of space, time and movement. Acta Psychologica, 11, $360-372$.

Fraisse, P. 1966 L'estimation de la durée. In F. Bresson, \& M. de Montmollin (Eds.), Psychologie et epistémologie génétiques: Thèmes Piagétiens. Paris: Dumond.

Fraisse, P. 1967 Psychologie du temps. 2nd ed. Paris: Presses Universitaire de France.

Fraisse, P., \& Vautrey, P. 1952a La perception de l'espace et la vitesse et du temps chez l'enfant de cinq ans. I. L'espace et la vitesse. Enfance, 5, 1-20.

Fraisse, P., \& Vautrey, P. $1952 b$ La perception de l'espace et la vitesse et du temps chez l'enfant de cinq ans. II. Le temps. Enfance, 5, 102-119.

LEBENSFELD, P., \& WAPNER, \$. 1968 Configuration and space-time interdependence. American Journal of Psychology, 81, 106-110.

Matsuda, F. 1968 Developmental study of 
time, space and velocity estimation: I. Japanese Joumal of Psychology, 39, 57-66. (In Japanese with English summary)

Matsuda, F, 1969 Developmental study of time, space and velocity estimation: II. Time and space estimations. Japanese fournal of Psychology, 40, 173-181. (In Japanese with English summary)

Matsuda, F. 1970 Developmental study of time, space and velocity estimations: IV. Set to use cue in time estimation. Japanese Journal of Psychology, 41, 182-194. (In Japanese with English summary)

Matsuda, F. 1971 Developmental study of time, space and velocity estimations: V. Set to use cue in space estimation. Japanese Journal of Psychology, 42, 233--245. (In Japanese with English summary)

Matsuda, F. 1974 Effects of space and velocity on time estimation in children and adults. Psychological Reseach, 37, 107-123.

Matsuda, F. 1977 Eflects of time and velocity on path-length estimation in children and adults. Studia Psychologica, 19, 19-31.

Matsuda, F., \& Matsuda, M. 1979 Kappa. effect and spatial separation as cue. Bulletin of the Faculty of Home Economics, Hiroshima Women's Cniversity, No. 14, 33-38. (In Japanese with English summary)

Newman, C. V., \& LeE, S. G, 1972 The effect of real and imputed distance on judgments of time: Some experiments on the Kappa phenomenon. Psychonomic Scicnce, 29, 207-211.

ONo, A. 1968 a Interdependence in judgements of the duration and distance of a manual movement. A developmental study. Memoirs of
Osaka University of Education, 17, 4, 49-58.

ONO, A 1968b Child's comparative judgements of duration of manual movement. Tohoku Psychologica Folia, 26, 107-115.

Ono, A. 1975 Étude expérimentale des interrelations entre temps, distance et vitesse subjectifs, Etude de l'effet Kappa-Tau. Journal de Psychologie, No. 3, 261-290.

PARKs, T.E. 1968 The spatial separation of two light-flashes and their perceived separation in time. Anerican Journal of Psychology, 81, 92-98.

Piacet, J. 1957 Les notions de vitesse, d'espace parcouru et de temps chez l'enfant de cinq ans. Enfance, 10, 9-42.

Piaget, J. 1961 Les mécanismes perceptifs. Paris: Presses Universitaire de France.

Praget, J. 1969 The child's conception of time (Trs. by A.J. Pomerans) London: Routledge \& Kegan Paul.

Price-Williams, D. R. 1954 The kappa effect. Nature, 73, 363-364.

Sudo, Y. 1941 On the effect of the phenomenal distance upon time estimation. Japanese 7ournal of Psychology, 16, 95-115. (In Japanese)

Voyat, G, 1963 La perception du temps. Étude d'estimation de durées brèves. Archives de

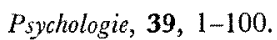

Zuilx, N., \& Frausse, P. 1966 L'estimation du temps en fonction de la quantité de mouvements effectués dans une tache. Étude génétique. L'Année Psychologique, 66, 383-396.

Zuilr, N., \& Fraisse, P. 1969 Le rôle des indices perçus dans la comparaison des durées chez l'enfant. L'Année Psychologique, 69, 16-36.

(Received Dec. 27, 1978) 